\title{
Optimization of Ultrasound-Assisted Extraction of Phenolic Antioxidants from Lotus corniculatus
}

\author{
Barbara Fumić, ${ }^{1,2}$ Mario Jug, ${ }^{3}$ Marijana Zovko Končić1,*
}

\author{
1 Department of Pharmacognosy, Faculty of Pharmacy and Biochemistry, University of Zagreb, A. Kovačića 1, HR-10000 Zagreb, Croatia \\ 2 Xellia Pharmaceuticals, Slavonska avenija, HR-10000, Zagreb, Croatia \\ 3 Department of Pharmaceutical Technology, Faculty of Pharmacy and Biochemistry, University of Zagreb, A. Kovačića 1, HR-10000 Zagreb, Croatia \\ * Corresponding author's e-mail address: mzovko@pharma.hr
}

RECEIVED: July 8, 2019 * REVISED: August 4, 2019 * ACCEPTED: August 5, 2019

\begin{abstract}
Ultrasound-assisted extraction of phenolic antioxidants from Lotus corniculatus was optimized using response surface methodology. The extraction was performed according to the Box-Behnken design with ethanol concentration, temperature, and $\mathrm{pH}$, as independent variables. The responses were extraction yield, DPPH radical scavenging activity (RSA) I $C_{50}$ and content of different phenolic compounds (total phenols, flavonoids and phenolic acids, as well as quercetin, kaempferol and genistein derivatives). The models were used to calculate best conditions for maximal extraction of phenolic compounds and antiradical activity. Use of the optimized extraction parameters increased the content of quercetin and kaempferol derivatives more than tenfold (from 6.07 to $65.10 \mathrm{mg} \mathrm{mL}^{-1}$ and 6.69 to $92.75 \mathrm{mg} \mathrm{mL}^{-1}$, respectively). The results of this work stress the importance of careful selection of conditions for flavonoids extraction. Abundance of bioactive phenolics in L. corniculatus extracts obtained under optimized extraction conditions opens the possibility for wider utilization of this plant.
\end{abstract}

Keywords: genistein, kaempferol, Lotus corniculatus, quercetin, radical scavenging activity, response surface methodology.

\section{INTRODUCTION}

T HE contemporary explosion of interest in healthy foods has caused a rapid growth of global food supplement sales. The popularity of botanicals-based supplements has caused an increased interest in extraction of plant bioactive components for the utilization in the preparation of functional food ingredients, food additives, pharmaceutical, and cosmetic products. ${ }^{[1]}$ Among all the plant phytochemicals flavonoids seem to be the most popular group, with the number of flavonoids-related scientific papers rising in an exponential manner over the last 25 years, much faster than the papers related to other food constituents. This interest was probably triggered by large epidemiological studies correlating flavonoids consumption with reduced incidence of cancer, stroke and coronary heart disease. For example, it has been found that quercetin and kaempferol display anti-inflammatory properties which have been connected to cancer and cardiovascular disease prevention. ${ }^{[2]}$ Such activity has also been observed with many of their glycosides because, upon the ingestion, flavonoid glycosides are hydrolyzed and further metabolized by intestinal enzymes or by the colonic microflora to the corresponding aglycones and their metabolites. As a result, the aglycone type and quantity are the dominant features which determine pharmacological effect of the flavonoids and the preparations that contain them. ${ }^{[3]}$

Lotus corniculatus L., Fabaceae (birdsfoot trefoil), is a perennial plant species with a wide distribution throughout the world. Besides being widely cultivated and used for forage production, ${ }^{[4]}$ the leaves of this plant are also used in human diet. ${ }^{[5]}$ The plant is used in traditional medicine as febrifuge, dermatic, ${ }^{[5]}$ anti-inflammatory, antispasmodic, cardiotonic, carminative, hypoglycemic, restorative, sedative, tonic and vermifuge agent. ${ }^{[6,7]}$ In vitro studies have demonstrated good anti-inflammatory ${ }^{[8]}$ and antimicrobial activity ${ }^{[9]}$ of $L$. corniculatus, as well as its lectin-induced apoptotic activity in various human tumor cell lines. ${ }^{[10]}$ In addition to that, the diet consisting of $L$. corniculatus increased reproductive efficiency in ewes. ${ }^{[11]}$ Bioactive constituents in $L$. corniculatus include lipid antioxidants such as $\alpha$-tocopherol, $\beta$-carotene, lutein ${ }^{[12]}$ and oleanolic 
acid. ${ }^{[9]}$ However, the most notable among numerous constituents of $L$. corniculatus are various phenolic compounds such as flavonoids, predominantly derivatives of kaempferol and quercetin ${ }^{[4,9]}$ and condensed tannins. ${ }^{[11]}$ Furthermore, the leaves are rich in vitamin $\mathrm{C}$ and proteins. ${ }^{[5]}$

Ultrasound-assisted extraction (UAE) is an inexpensive, rapid, simple and efficient technique for extraction, most often used for solid/liquid systems. In comparison to conventional techniques for food and natural products extraction, UAE is characterized by decrease of $\mathrm{CO}_{2}$ emissions, extraction and processing time, as well as the amount of energy and solvents used. However, for determining the best UAE conditions for extraction of bioactive constituents, it is necessary to perform multiple experiments and to evaluate, not only the direct influence of extraction conditions, but their interactions as well. In order to reduce the number of such experiments, response surface methodology (RSM) is frequently used. It is a collection of mathematical and statistical techniques aimed at creating a functional relationship and empirical model between the response(s) of interest and a number of associated input variables. RSM is frequently applied for optimization of UAE of natural antioxidants. Extraction of phenolic acids from potatoes, ${ }^{[13]}$ anthocyanins from red beet ${ }^{[14]}$ and phenolics from soy, ${ }^{[15]}$ are only a few among numerous examples of successful RSM use for optimization of phenolic compounds extraction.

L. corniculatus is an edible plant containing numerous beneficial phytochemicals, suitable for inclusion in food supplements or functional foods. However, the detailed analysis of the extraction procedure needed for development of such products is still lacking. The aim of this work was to select and validate optimum conditions for extraction of different classes of phenolic compounds and radical scavengers from $L$. corniculatus by studying the combined effects of selected extraction parameters: ethanol concentration $\left(\mathrm{X}_{1}\right)$, temperature $\left(\mathrm{X}_{2}\right)$, and $\mathrm{pH}\left(\mathrm{X}_{3}\right)$.

\section{EXPERIMENTAL}

\section{Plant Materials and Chemicals}

Aerial parts of $L$. corniculatus were collected in the sur-

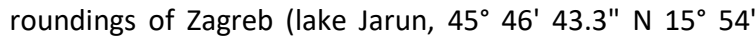
$\left.46.8^{\prime \prime} \mathrm{E}\right)$. The samples were dried and stored in a well-ventilated room, protected from light. Plant material was identified by Vedran Šegota, expert associate at the Department of Botany, Faculty of science, University of Zagreb. Voucher specimen (DF-LC1-05-2013) is deposited in the Department of Pharmacognosy, Faculty of Pharmacy and Biochemistry, University of Zagreb, Zagreb, Croatia. Folin-Ciocalteu phenol reagent, 2,2-diphenyl-1picrylhydrazyl (DPPH), gallic acid monohydrate ( $\geq 99 \%)$, genistein ( $\geq 97 \%$ ), kaempferol $\geq 97.0 \%$, and quercetin dihydrate ( $\geq 98 \%$ ) were purchased from Sigma-Aldrich (US). Methanol was HPLC grade. Other reagents and chemicals were of analytical grade.

\section{Preparation of Extracts}

The dried aerial parts of $L$. corniculatus were milled and passed through a sieve of $850 \mu \mathrm{m}$ mesh size. Powdered plant material $(2 \mathrm{~g})$ was suspended with $25 \mathrm{~mL}$ of the appropriate solvent in a $50 \mathrm{~mL}$ Erlenmeyer flask. $\mathrm{pH}$ of the solvent was previously adjusted using the appropriate amount of either $1 \mathrm{M} \mathrm{NaOH}$ or $1 \mathrm{M} \mathrm{HCl}$. The extraction was performed in an ultrasonic bath (Bandelin SONOREX Digital 10 P DK 156 BP, Germany) at ultrasonication power of $720 \mathrm{~W}$ and frequency of $35 \mathrm{~Hz}$. The bath was temperaturecontrolled according to the extraction conditions presented in Table 1. Upon the extraction, the mixture was filtered using folded filter paper S\&S 589/1 1/2 and diluted with the same solvent to a volume of $25.0 \mathrm{~mL}$. All the extracts were stored at $+4{ }^{\circ} \mathrm{C}$ in the dark until use. The yield was determined as the weight $(\mathrm{mg})$ of dry matter in $1 \mathrm{~mL}$ of the extract $(w / v)$.

\section{Spectrophotometric Determinations of Total Phenol, Flavonoid and Phenolic Acid Content}

Total phenol content (TP) in the extracts was determined according to modified Folin-Ciocalteau colorimetric method. ${ }^{[16]}$ Folin Ciocalteu reagent $(100 \mu \mathrm{L})$ and $10 \%$ $\mathrm{Na}_{2} \mathrm{CO}_{3}$ solution $(100 \mu \mathrm{L})$ were added to $100 \mu \mathrm{L}$ of the extract solution. After $1 \mathrm{~h}$ the absorbance was measured at $630 \mathrm{~nm}$. Total flavonoid content (TF) was assessed by modified method of Kumazawa ${ }^{[17]}$ by adding $120 \mu \mathrm{L}$ of extract solution to $120 \mu \mathrm{L}$ of $0.2 \% \mathrm{AlCl}_{3}$ solution in methanol. After $1 \mathrm{~h}$, the absorbance was measured at $405 \mathrm{~nm}$. Total phenolic acid content (TPA) was determined as described Nicolle et al. ${ }^{[18]}$ with minor modifications. To $100 \mu \mathrm{L}$ of extract solution $50 \mu \mathrm{L}$ of each reagent $0.5 \mathrm{M} \mathrm{HCl}$, nitritemolibdate reagent and $8.5 \% \mathrm{NaOH}$ were added. The amounts of TP, TF and TPA were expressed as gallic acid, quercetin and caffeic acid equivalents, respectively, using the corresponding standard calibration curves. Measurements were performed using Stat Fax 3200 (Awareness Technologies, USA) microplate reader.

\section{HPLC Analysis of Quercetin, Kaempferol and Genistein Derivatives}

Prior to the HPLC analysis, flavonoid glycosides in the extracts were hydrolyzed by addition of $400 \mu \mathrm{L}$ of $5 \mathrm{M} \mathrm{HCl}$ to $1 \mathrm{~mL}$ of extract in a hermetically sealed tube. The solution was heated for $2 \mathrm{~h}$ in boiling water bath ${ }^{[19]}$ and filtered through a $0.45 \mu \mathrm{m}$ PTFE syringe filter. Upon the hydrolysis, the mixture was allowed to cool down to room 
temperature. Flavonoid aglycones were quantified using the Agilent 1200 series HPLC instrument (Agilent Technologies, USA) equipped with a DAD detector and an Zorbax Eclipse XDB-C18 ( $5 \mu \mathrm{m}, 12.5 \mathrm{~mm} \times 4.6 \mathrm{~mm}$, Agilent) column. Injection volume was $20 \mu$ l. Mixture of water, methanol and formic acid used in ratios of $93: 5: 2(\mathrm{~V} / \mathrm{V} / \mathrm{V})$ and $3: 95: 2$ $(V / V / V)$ was used as mobile phase $A$ and $B$, respectively. Separation was performed at $40^{\circ} \mathrm{C}$ using the following protocol: 0 min $20 \%$ B, $10 \min 40 \%$ B and $35 \min 50 \%$ B. Flow rate was $1.0 \mathrm{~mL} \mathrm{~min}{ }^{-1}$. The peak assignment and identification was based on comparison of UV/VIS spectra and retention times of peaks in sample chromatogram with those of the standards. Quantification was performed using the respective standard calibration curve. The following calibration curves were obtained: genistein $\left(y=743.33 x, r^{2}=\right.$ 0.99997) (at $254 \mathrm{~nm}$ ), kaempferol $\left(y=2823.87 x, r^{2}=\right.$ $0.99999)$ (at $254 \mathrm{~nm}$ ) and quercetin $\left(y=3069.92 x, r^{2}=\right.$ 0.99972 ) (at $320 \mathrm{~nm}$ ), where $y$ is the absorbance at the selected wavelength, $x$ is the weight of flavonoid $(\mu \mathrm{g})$ and $r^{2}$ is the coefficient of determination. Limit of detection (LD) and limit of quantification (LQ), determined according to, ${ }^{[20]}$ were as follows: quercetin $(\mathrm{LD}=0.0275 \mu \mathrm{g}, \mathrm{LQ}=$ $0.0833 \mu \mathrm{g})$, genistein $(\mathrm{LD}=0.0097 \mu \mathrm{g}, \mathrm{LQ}=0.0293 \mu \mathrm{g})$ and kaempferol ( $\mathrm{LD}=0.0038, \mu \mathrm{g}, \mathrm{LQ}=0.0115 \mu \mathrm{g})$.

\section{Free Radical Scavenging Activity}

Free radical scavenging activity (RSA) was evaluated using DPPH free radical. The assay was performed as described in. ${ }^{[21]}$ Methanolic DPPH solution $\left(70 \mu \mathrm{l}, 0.2 \mathrm{mg} \mathrm{mL}^{-1}\right)$ was added to $130 \mu$ l of either the methanolic solution of the extract (sample) or methanol (control). The mixture was left at room temperature in the dark place. After $30 \mathrm{~min}$ absorbance was read at $545 \mathrm{~nm}$. BHA was used as a positive control. RSA for DPPH free radical was calculated according to the [Eq. (1)]:

$$
\text { RSA }=\frac{A_{\text {control }}-A_{\text {sample }}}{A_{\text {control }}} \times 100
$$

where $A_{\text {control }}$ is the absorbance of the control and $A_{\text {sample }}$ is the absorbance of the DPPH solution containing extract. Seven dilutions of each extract were tested. Concentration of the extract which scavenges $50 \%$ of DPPH free radicals present in the solution (RSA $I C_{50}$ ) was calculated and expressed as $\mathrm{mg}$ of herbal material equivalents per $\mathrm{mL}$ of the extract (mg HME $\mathrm{mL}^{-1}$ ).

\section{Experimental Design}

A three-level-three-factor, Box-Behnken design (BBD) was employed to determine the best combination of independent extraction variables for the selected dependent variables (responses). The following design parameters were used (coded values are given in brackets): ethanol concentration $(v / v)\left(X_{1}\right)$ was between $0 \%(-1)$ and $100 \%$ $(+1)$; temperature $\left(X_{2}\right)$ was between $20{ }^{\circ} \mathrm{C}(-1)$ and $60{ }^{\circ} \mathrm{C}$ $(+1)$; $\mathrm{pH}$ of extraction solvent $\left(\mathrm{X}_{3}\right)$ was between $5.5(-1)$ and $8.5(+1)$. Extraction yield, TP, TF, TPA, total genistein, kaempferol, and quercetin derivatives, as well as RSA IC 50 were selected as the responses. Experimental data were fitted to a quadratic polynomial model as described by the following quadratic equation (2):

$Y=A_{0}+\sum_{i=1}^{k} A_{i} X_{i}+\sum_{i=1}^{k} A_{i j} X_{i}^{2}+\sum_{i=1}^{k-1} \times \sum_{j=1+1}^{k} A_{i j} X_{i} X_{j}$

where $Y$ is the dependent variable; $A_{0}, A_{\mathrm{i}}, A_{\mathrm{ij}}$, and $A_{\mathrm{ij}}$ are the regression coefficients for intercept, linearity, square and interaction, respectively, while $X_{\mathrm{i}}$ and $X_{\mathrm{j}}$ are the independent variables. The data was analyzed by multiple regression analysis and by the analysis of variance (ANOVA) for the selected models. $P$ values $<0.05$ were considered statistically significant. Measurements were performed in triplicates and the mean value reported. Design Expert software version 8.0.6 (Stat-Ease, Minneapolis) was employed for the regression analysis and the optimization of the results.

\section{RESULTS AND DISCUSSION}

\section{Extraction Conditions and Model Fitting}

Dietary phenols, as well as their metabolites, may reduce the risk for the development of type 2 diabetes complications, cardiovascular diseases or even cancer. ${ }^{[22]}$ Therefore, the focus of this work was on optimizing the extraction of natural phenols from L. corniculatus. The nature of solvent, especially its polarity and viscosity, are the key factors that impact the extraction efficiency. Due to their wide availability, biodegradability and relatively low toxicity, the ethanol/water mixtures are among the most used eco-friendly solvents for the extraction of medicinal plants bioactive principles, including phenolic compounds. ${ }^{[23]}$ In addition to solvent, temperature is another important UAE variable. High temperature may improve the extraction process by reducing the viscosity of the solvent and increasing kinetic energy of the molecules in the solution. However, high temperature may also lead to degradation of sensitive phytochemicals, including phenolic compounds. In addition to temperature, $\mathrm{pH}$ of the solvent can also influence the extraction efficiency. For example, $\mathrm{pH}$ changes may cause ionization of weak acids and bases, thus increasing their solubility in water. However, extreme $\mathrm{pH}$ values, especially in combination with ultrasonication, can also contribute to degradation of the target compounds. ${ }^{[24]}$

In this work the extraction solvent (water/ethanol ratio), temperature and $\mathrm{pH}$ were selected as independent 
variables and their influence on the extraction efficiency investigated. The experimental procedure followed BoxBehnken design. The selected responses were extraction yield, RSA IC 50 , as well as the content of phenolic constituents (phenols, flavonoids, phenolic acids, as well as quercetin, kaempferol and genistein derivatives). Table 1 shows the process variables and experimental results of 17 runs. The ANOVA (Table 2) has shown that the relationship between the response variables and independent variables can be satisfactorily expressed using the quadratic polynomial equations (Table 3 ). The significance of each model was calculated using the $F$-test and $P$-values. The calculated $F$-values were higher than 7.5 , while the $P$-values were lower than 0.05 . This indicates that the models are significant and that they can be used to optimize the extraction variables. Lack-of-fit in the models was statistically

Table 1. Independent variables, their levels for Box-Behnken design and the responses obtained.

\begin{tabular}{|c|c|c|c|c|c|c|c|c|c|c|c|}
\hline Run & $\begin{array}{l}X_{1} / \% \\
(v / v)\end{array}$ & $X_{2} /{ }^{\circ} \mathrm{C}$ & $x_{3}$ & $\begin{array}{c}\text { Yield / } \\
\mathrm{mg} \mathrm{mL}^{-1}\end{array}$ & $\begin{array}{c}\mathrm{TP} / \\
\mathrm{mg} \mathrm{mL}^{-1}\end{array}$ & $\begin{array}{c}\mathrm{TF} / \\
\mathrm{mg} \mathrm{mL}^{-1}\end{array}$ & $\begin{array}{c}\mathrm{TPA} / \\
\mathrm{mg} \mathrm{mL}^{-1}\end{array}$ & $\begin{array}{c}\text { Quercetine / } \\
\mathrm{mg} \mathrm{mL}^{-1}\end{array}$ & $\begin{array}{c}\text { Kaempferol / } \\
\mathrm{mg} \mathrm{mL}^{-1}\end{array}$ & $\begin{array}{c}\text { Genistein / } \\
\mathrm{mg} \mathrm{mL}^{-1}\end{array}$ & $\begin{array}{c}\mathrm{RSA} \mathrm{IC}_{50} / \\
\mathrm{mg} \mathrm{HME} \mathrm{mL}\end{array}$ \\
\hline 1 & $100(+1)$ & $60(+1)$ & $7.0(0)$ & 9.50 & 5.72 & 0.490 & 0.062 & 20.60 & 28.42 & 3.49 & 13.56 \\
\hline 2 & $50(0)$ & $60(+1)$ & $8.5(+1)$ & 16.75 & 8.65 & 0.413 & 0.112 & 65.98 & 92.31 & 15.22 & 11.22 \\
\hline 3 & $0(-1)$ & $60(+1)$ & $7.0(0)$ & 15.75 & 7.39 & 0.186 & 0.060 & 14.30 & 19.41 & 2.96 & 8.51 \\
\hline 4 & $0(-1)$ & $40(0)$ & $5.5(-1)$ & 15.75 & 6.58 & 0.174 & 0.070 & 6.07 & 6.69 & 2.30 & 11.90 \\
\hline 5 & $0(-1)$ & $20(-1)$ & $7.0(0)$ & 15.50 & 5.80 & 0.131 & 0.060 & 14.80 & 19.95 & 4.01 & 21.30 \\
\hline 6 & $0(-1)$ & $40(0)$ & $8.5(+1)$ & 14.50 & 7.05 & 0.182 & 0.055 & 8.35 & 10.43 & 2.58 & 21.33 \\
\hline 7 & $100(+1)$ & $40(0)$ & $5.5(-1)$ & 9.25 & 3.80 & 0.446 & 0.054 & 20.86 & 26.17 & 3.55 & 11.70 \\
\hline 8 & $50(0)$ & $40(0)$ & $7.0(0)$ & 17.00 & 9.23 & 0.386 & 0.102 & 49.11 & 71.28 & 12.60 & 12.91 \\
\hline 9 & $100(+1)$ & $20(-1)$ & $7.0(0)$ & 6.25 & 4.05 & 0.408 & 0.062 & 14.23 & 17.87 & 2.34 & 14.29 \\
\hline 10 & $50(0)$ & $20(-1)$ & $8.5(+1)$ & 16.00 & 8.57 & 0.376 & 0.103 & 50.28 & 69.36 & 11.96 & 28.62 \\
\hline 11 & $50(0)$ & $40(0)$ & $7.0(0)$ & 17.25 & 9.36 & 0.382 & 0.112 & 46.80 & 68.14 & 11.66 & 12.58 \\
\hline 12 & $50(0)$ & $40(0)$ & $7.0(0)$ & 18.00 & 8.81 & 0.393 & 0.110 & 53.05 & 76.38 & 12.61 & 9.56 \\
\hline 13 & $100(+1)$ & $40(0)$ & $8.5(+1)$ & 8.50 & 5.02 & 0.458 & 0.059 & 10.16 & 11.54 & 2.24 & 16.57 \\
\hline 14 & $50(0)$ & $40(0)$ & $7.0(0)$ & 16.00 & 8.28 & 0.411 & 0.082 & 51.74 & 76.09 & 12.69 & 13.20 \\
\hline 15 & $50(0)$ & $60(+1)$ & $5.5(-1)$ & 16.00 & 8.26 & 0.361 & 0.090 & 52.92 & 78.18 & 12.75 & 9.56 \\
\hline 16 & $50(0)$ & $20(-1)$ & $5.5(-1)$ & 17.00 & 9.41 & 0.401 & 0.112 & 44.99 & 70.40 & 10.69 & 13.54 \\
\hline 17 & $50(0)$ & $40(0)$ & $7.0(0)$ & 17.25 & 8.78 & 0.375 & 0.090 & 55.96 & 82.68 & 13.70 & 12.54 \\
\hline
\end{tabular}

$X_{1}-$ Ethanol concentration; $X_{2}-$ Temperature; $X_{3}-\mathrm{pH}$ of extraction solvent:

TP - total phenol content; TF - total flavonoid content; TPA - total phenolic acid content; RSA - radical scavenging activity, HME - herbal material equivalents.

Table 2. Analysis of variance (ANOVA) for the fitted quadratic models for optimization of $L$. corniculatus extraction process.

\begin{tabular}{|c|c|c|c|c|c|c|c|c|c|c|c|c|c|c|c|c|c|c|c|c|c|c|}
\hline \multirow[b]{2}{*}{ Source } & \multicolumn{6}{|c|}{ Yield $\left(r^{2}=0.9749\right)$} & \multicolumn{5}{|c|}{$\operatorname{TP}\left(r^{2}=0.9303\right)$} & \multicolumn{6}{|c|}{$\operatorname{TF}\left(r^{2}=0.9826\right)$} & \multicolumn{5}{|c|}{$\operatorname{TPA}\left(r^{2}=0.9064\right)$} \\
\hline & SS & $d f$ & MS & & $\mathrm{F}$ & $P$ & SS & & $\mathrm{MS}$ & $\mathrm{F}$ & $P$ & SS & df & MS & $\mathrm{F}$ & F & $P$ & SS & $d f$ & MS & $\mathrm{F}$ & $P$ \\
\hline Model & 207.09 & 9 & 23.01 & & $0.16<$ & $<10^{-4}$ & 51.6 & & 5.741 & 10.39 & 90.0027 & 0.190 & 9 & 0.021 & 43. & $.97<$ & $<10^{-4}$ & 0.008 & 9 & 0.00084 & 47.53 & 0.007 \\
\hline LoF & 3.27 & 3 & 1.09 & & 10 & 0.24 & 3.15 & & 1.05 & 5.80 & 0.0614 & 0.003 & 3 & 0.001 & 4.7 & 76 & 0.0830 & 0.0001 & 3 & 0.00004 & 40.26 & 0.852 \\
\hline \multirow[t]{2}{*}{ PE } & 2.08 & 4 & 0.52 & & & & 0.72 & 2 & 0.18 & & & 0.001 & 4 & 0.0002 & & & & 0.0006 & 4 & 0.00016 & & \\
\hline & \multicolumn{5}{|c|}{ Quercetin $\left(r^{2}=0.9716\right)$} & \multicolumn{7}{|c|}{ Kaempferol $\left(r^{2}=0.9829\right)$} & \multicolumn{5}{|c|}{ Genistein $\left(r^{2}=0.9787\right)$} & \multicolumn{5}{|c|}{ RSA IC $50\left(r^{2}=0.9567\right)$} \\
\hline Source & SS & df & MS & $\mathrm{F}$ & $P$ & SS & & $d f$ & & MS & $\mathrm{F}$ & $P$ & SS & $d f$ & MS & $\mathrm{F}$ & $P$ & SS & $d f$ & MS & $\mathrm{F}$ & $P$ \\
\hline Model & 6630.4 & 97 & 736.72 & 26.6 & $<10^{-4}$ & 41511 & 19.9 & 9 & 1679 & 9.991 & $43.283<$ & $<0.0001$ & 407.63 & 9 & 45.29 & 35.82 & $2<10^{-4}$ & 401.05 & 9 & 44.5617 & 17.054 & 0.0006 \\
\hline LoF & 143.90 & 32 & 47.973 & 3.84 & 0.11 & 148.7 & .73 & 3 & 49.5 & 5761 & 1.613 & 0.3200 & 6.76 & 3 & 2.25 & 4.31 & 0.096 & 9.59 & 3 & 3.201 & 1.470 & 0.349 \\
\hline$P E$ & 50.02 & 41 & 12.51 & & & 122. & .97 & 4 & 30.7 & 7426 & & & 2.09 & 4 & 0.52 & & & 8.70 & 4 & 2.17 & & \\
\hline
\end{tabular}

SS = Sum of Squares; $d f$ = degrees of freedom; MS = Mean Square. LoF = Lack of fit; PE = pure error; RSA = radical scavenging activity

TP - Total phenol content; TF - Total flavonoid content; TPA - Total phenolic acid content; RSA - Radical scavenging activity. 
insignificant relative to the pure error which demonstrated that the fitting model is adequate to describe the experimental data. The determination coefficients $\left(r^{2}\right)$ were relatively high $\left(0.9303 \leq r^{2} \leq 0.9829\right)$ showing that the observed values are well replicated by the model. Details are discussed below.

\section{Yield of the Extraction}

The yield, calculated as amount of dry matter in the extracts, was greatly affected by the extraction conditions. The results, presented in Table 1 , show that the yield ranged from $6.25 \mathrm{mg} \mathrm{mL}^{-1}$ to $18.00 \mathrm{mg} \mathrm{mL}^{-1}$ in run 9 and run 12 , respectively, which is almost a threefold change in the content of dry matter between extracts. In general, pure ethanol was the least efficient solvent for the constituents of $L$. corniculatus, while water and $50 \%$ ethanol extracted similar amounts of dry matter. Even though the extraction yield of some plants from Fabaceae family such as Medicago sativa may be influenced by $\mathrm{pH}$ and temperature, ${ }^{[21]}$ the equation in terms of coded factors (Table 3 ) shows that the yield in this study was significantly influenced only by ethanol content both as linear and quadratic term.

\section{Total Phenol, Flavonoid and Phenolic Acid Content}

In this work, UAE was utilized to efficiently extract the phenolic compounds from $L$. corniculatus aerial parts. Besides determining the amount of total phenols, the content of two sub-groups of phenols, flavonoids and phenolic acids, was also assessed and presented in Table 1. The amount of TP in the prepared extracts varied significantly from
$3.80 \mathrm{mg} \mathrm{mL}^{-1}$ to $9.41 \mathrm{mg} \mathrm{mL}^{-1}$, in run 7 and run 16 , respectively. TPA constituted rather small amount of total phenols and their amount rarely exceeded $0.1 \mathrm{mg} \mathrm{mL}^{-1}$. The concentration of flavonoids, on the other hand, was higher and varied from $0.131 \mathrm{mg} \mathrm{mL}^{-1}$ to $0.490 \mathrm{mg} \mathrm{mL}^{-1}$. In this study, TF and TPA accounted for only a small portion of TP. Even though the detailed analysis of all the phytochemical components of the prepared extracts is out of scope of this work, in accordance with the previous literature findings, ${ }^{[11]}$ such high TP is probably due to condensed tannins that $L$. corniculatus is rich in. It is important to stress that TP was assessed though the reaction with Folin-Ciocalteu reagent. The results obtained by using this reagent are most often interpreted as the total amount of phenolic compounds. However, numerous compounds with reducing abilities may also react with this reagent. Therefore, this assay is sometimes considered as one of the antioxidant capacity assays, rather than a selective assay for phenolic compounds. ${ }^{[25]}$ For example, vitamin $\mathrm{C}$ and proteins, that the $L$. corniculatus leaves are rich in, ${ }^{[5]}$ may also give positive reaction with Folin-Ciocalteu reagent leading to seemingly higher TP content.

Similar to yield, TP and TF were significantly influenced by ethanol content as both linear and quadratic term (Table 3). Concentration of phenolic acids, on the other hand, was significantly dependent only on ethanol concentration as quadratic factor (Table 3). Even though extraction of TP and TF was slightly better at higher temperatures, especially at lower $\mathrm{pH}$, this effect did not reach statistical significance (Table 3). Previous studies have demonstrated the importance of ethanol concentration over other extraction factors, such as extraction time or temperature. ${ }^{[1]}$

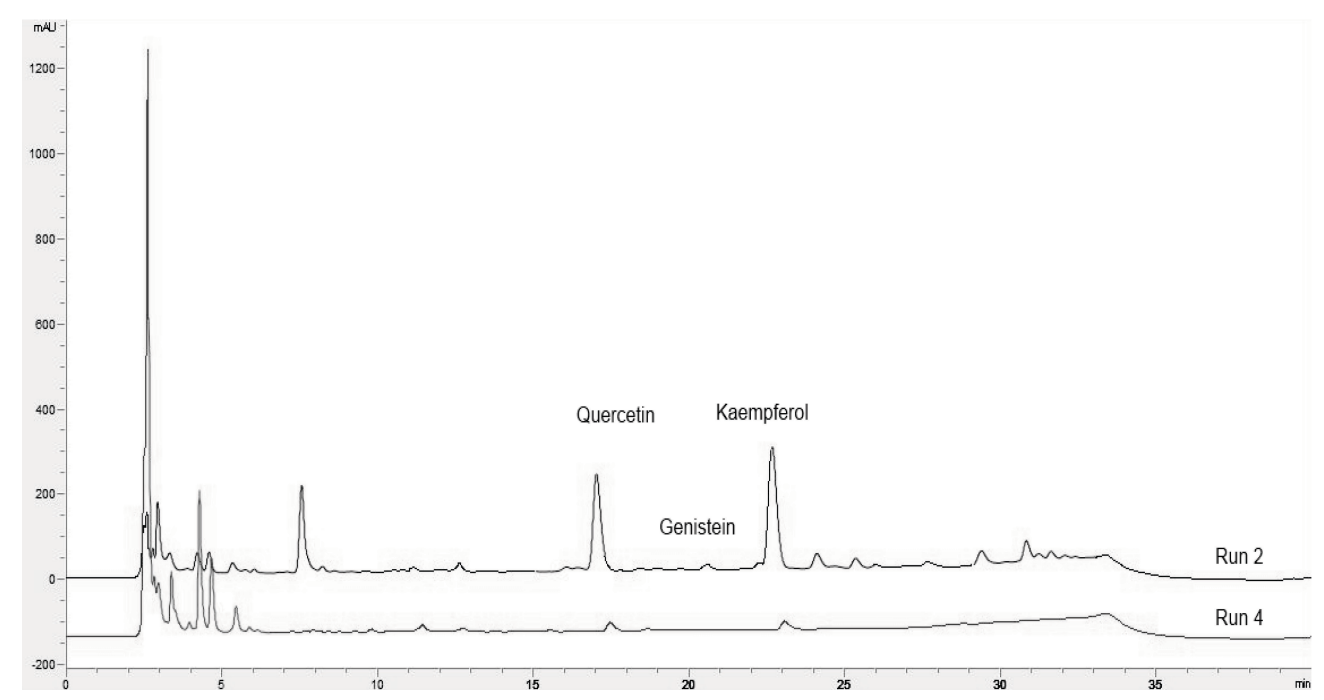

Figure 1. Change of quercetin, kaempferol and genistein concentration in the extract containing their lowest (Run 4) or highest (Run 2) concentration. 
However, other studies have also recorded a strong influence of extraction temperature and $\mathrm{pH}$ on the efficiency of ethanol UAE of phenolic compounds from different plant material, such as blackberry ${ }^{[26]}$ or bovine pennyroyal[27] leaves. Besides the differences in the extraction conditions e.g. somewhat larger $\mathrm{pH}$ and temperatures range used in the study Aybastıer et al., ${ }^{[26]}$ it seems that the difference in phenolic composition of those plants is also partly responsible for the observed response to the extraction conditions. Therefore, in order to achieve optimal response the extraction conditions should be carefully selected and adjusted to each plant individually.

\section{Quercetin, Kaempferol and Genistein Derivatives}

L. corniculatus is a rich source of flavonoids, especially kaempferol and quercetin derivatives. ${ }^{[7]}$ As reported above, the flavonoid content was analyzed spectrophotometrically. However, even though the results of spectroscopic analysis of flavonoids with aluminum ions may give useful first estimate of the flavonoid content, they are not entirely appropriate as universal and standard methods for total flavonoid determination. ${ }^{[28]}$ This is mostly due to variability of flavonoid aglycone structures, as well as presence and position of sugars in flavonoid glycosides. Therefore, to study the influence of extraction conditions on kaempferol and quercetin derivatives content in this work, they were quantified using an HPLC-DAD method. In most plant species, flavones are contained in form of glycosides and L. corniculatus is not an exception. ${ }^{[4]}$ Analysis of flavonoid glycosides may be demanding and, in case of the lack of appropriate standard, their concentration may be underestimated. Therefore, instead of quantifying the individual flavonoid derivatives, the extracts were subjected to acidmediated hydrolysis and the content of main flavonoid aglycones determined (Table 1).
In accordance with the previous studies, HPLC analysis confirmed that the main flavonoids were quercetin and kaempferol derivatives. Their concentrations were significantly dependent only on ethanol concentration as quadratic factor (Table 3). Moreover, the content of quercetin and kaempferol derivatives varied more than tenfold (from 6.07 to $65.10 \mathrm{mg} \mathrm{mL}^{-1}$ and 6.69 to $92.75 \mathrm{mg} \mathrm{mL}^{-1}$, respectively) depending on ethanol concentration in the extracts (Fig. 1), which further corroborates the importance of extraction conditions for successful extraction of the phenolic compounds. Similar to findings presented in this work, ethanol concentration was the most important parameter for combined extraction of quercetin and kaempferol derivatives from other plant materials, such as Fructus sophorae. ${ }^{[1]}$ Even though the previous studies recorded absence of genistein in L. corniculatus, ${ }^{[29]}$ small amounts of that isoflavone were also detected and quantified. Genistein is known to have multiple molecular effects, such as the inhibition of inflammation, carcinogenesis, obesity, osteoporosis, and metabolic syndrome. ${ }^{[30]}$ Furthermore, it has been reported to improve skin changes caused by aging. ${ }^{[31]}$ Similar to quercetin and kaempferol, the amount of extracted genistein derivatives depended only on ethanol concentration as quadratic factor (Table 3 ). It is important to note that in the solutions prepared either with pure water or pure ethanol genistein peak was almost negligible (Fig. 1), which may be one of the reasons why this isoflavonoid was unnoticed in previous studies. ${ }^{[29]}$ This indicates that extraction optimization is an imperative for proper detection and quantification of phytochemicals in natural material.

\section{Radical Scavenging Activity of the Extracts}

Radical scavenging activity of the extracts was investigated using DPPH free radicals. The reactivity of antioxidants with $\mathrm{DPPH}$ free radicals is related to their ability to donate a

Table 3. Polynomial equations in terms of coded factors for extraction responses.

\begin{tabular}{|c|c|c|}
\hline Rsp. & Unit & Equation \\
\hline Y & $\mathrm{mg} \mathrm{mL} \mathrm{L}^{-1}$ & $Y=17.10-3.50 \times X_{1} *+0.41 \times X_{2}-0.28 \times X_{3}+0.75 \times X_{1} \times X_{2}+0.13 \times X_{1} \times X_{3}+0.44 \times X_{2} \times X_{3}-4.89 \times X_{1}^{2 *}-0.46 \times X_{2}^{2}-0.21 \times X_{3}^{2}$ \\
\hline TP & $m g ~ m L^{-1}$ & $Y=8.89-1.03 \times X_{1} *+0.28 \times X_{2}+0.16 \times X_{3}+0.02 \times X_{1} \times X_{2}+0.19 \times X_{1} \times X_{3}+0.31 \times X_{2} \times X_{3}-3.13 \times X_{1}^{2 *}-0.02 \times X_{2}^{2}-0.15 \times X_{3}^{2}$ \\
\hline TF & $\mathrm{mg} \mathrm{mL} \mathrm{L}^{-1}$ & $Y=0.39+0.14 \times X_{1} *+0.02 \times X_{2}+0.0 \times X_{3}+0.0 \times X_{1} \times X_{2}+0.01 \times X_{1} \times X_{3}+0.02 \times X_{2} \times X_{3}-0.08 \times X_{1}^{2 *}-0.01 \times X_{2}^{2}+0.01 \times X_{3}^{2}$ \\
\hline TPA & $m g ~ m L^{-1}$ & $Y=0.099-0.001 \times X_{1}-0.002 \times X_{2}+0.0002 \times X_{3}+0.00004 \times X_{1} \times X_{2}+0.005 \times X_{1} \times X_{3}+0.007 \times X_{2} \times X_{3}-0.041 \times X_{1}^{2 *}+0.003 \times X_{2}^{2}+0.001 \times X_{3}^{2}$ \\
\hline Q & $\mu \mathrm{g} \mathrm{mL^{-1 }}$ & $Y=51.33+2.79 \times X_{1}+3.69 \times X_{2}+1.24 \times X_{3}+1.72 \times X_{1} \times X_{2}-3.25 \times X_{1} \times X_{3}+1.94 \times X_{2} \times X_{3}-38.77 \times X_{1}^{2 *}-+3.42 \times X_{2}^{2}-1.2 \times X_{3}^{2}$ \\
\hline K & $\mu g \mathrm{~mL}^{-1}$ & $Y=74.92+3.44 \times X_{1}+5.09 \times X_{2}+0.27 \times X_{3}+2.77 \times X_{1} \times X_{2}-4.60 \times X_{1} \times X_{3}+3.79 \times X_{2} \times X_{3}-58.68 \times X_{1}^{2 *}+5.18 \times X_{2}^{2}-2.53 \times X_{3}^{2}$ \\
\hline G & $\mu g \mathrm{~mL}^{-1}$ & $Y=12.65-0.030 \times X_{1}+0.68 \times X_{2}+0.34 \times X_{3}+0.55 \times X_{1} \times X_{2}-0.04 \times X_{1} \times X_{3}+0.30 \times X_{2} \times X_{3}-9.72 \times X_{1}^{2 *}+0.27 \times X_{2}^{2}-0.26 \times X_{3}^{2}$ \\
\hline $\begin{array}{l}\text { RSA } \\
I_{50}\end{array}$ & 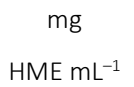 & $Y=12.16-0.86 \times X_{1}-4.36 \times X_{2} *+3.88 \times X_{3} *+3.01 \times X_{1} \times X_{2} *-1.14 \times X_{1} \times X_{3}-3.36 \times X_{2} \times X_{3} *+0.95 \times X_{1}^{2 *}+1.31 \times X_{2}^{2}+2.27 \times X_{3}^{2 *}$ \\
\hline
\end{tabular}

$\mathrm{X}_{1}=$ Concentration of ethanol in water $(v / v, \%) ; \mathrm{X}_{2}=$ Temperature $\left({ }^{\circ} \mathrm{C}\right) ; \mathrm{X}_{3}=\mathrm{pH} ;{ }^{*}=$ significant model terms as indicated by values of $\mathrm{P}<0.05$

Rsp. - response; $Y$ - yield; TP - Total phenol content; TF - Total flavonoid content; TPA - Total phenolic acid content; $Q$ - quercetin; $K$ - kaempferol;

$\mathrm{G}$ - genistein; RSA - radical scavenging activity; HME - Herbal material equivalents. 
hydrogen atom. This leads to a decrease in the absorbance of the DPPH radicals as determined spectrophotometrically at $517 \mathrm{~nm}$. It is a relatively simple method suitable for
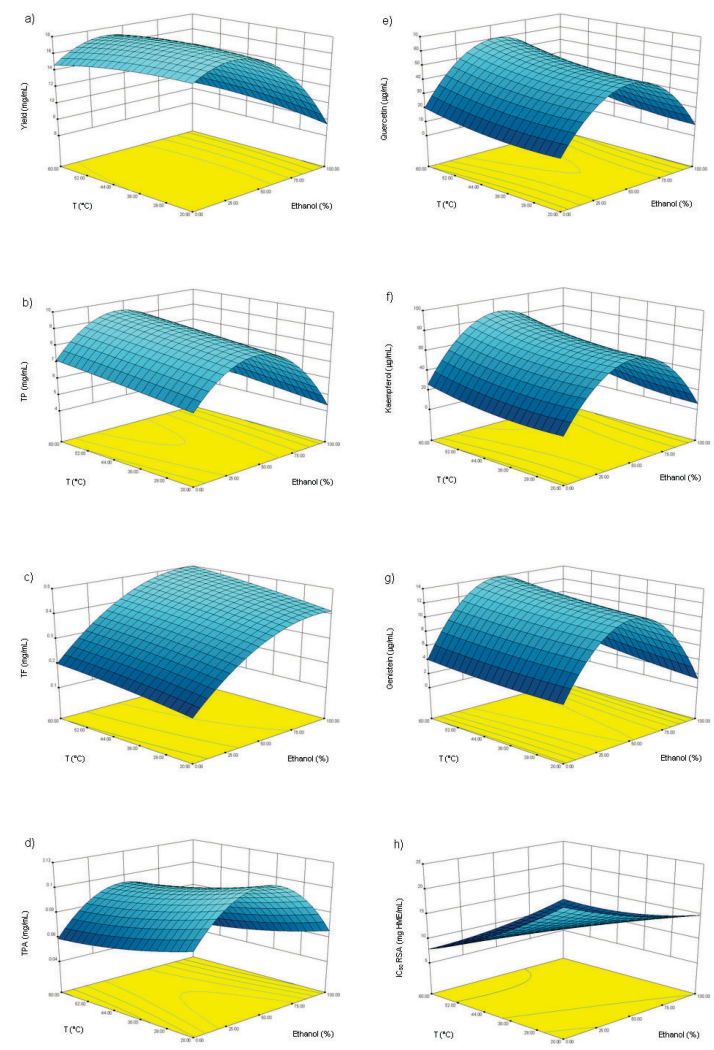

Figure 2. Response surface plots showing the optimum extraction conditions for maximal a) yield ( $\mathrm{pH} 5.5), \mathrm{b})$ TP $(\mathrm{pH}$ 8.0), c) TF ( $\mathrm{pH} 8.5)$, d) TPA ( $\mathrm{pH} 5.5)$, e) quercetin ( $\mathrm{pH} 8.5), \mathrm{f}$ ) kaempferol ( $\mathrm{pH} 8.5$ ) and $\mathrm{g}$ ) geinistein ( $\mathrm{pH} 8.5$ ) content, as well as minimal RSA IC 50 ( $\mathrm{pH} 7.0)$. determination of antiradical activity of a large number of natural extracts in a relatively short time, which makes this model one of the most commonly used in literature. In the presented work, RSA IC $C_{50}$ values of $L$. corniculatus extracts ranged between $8.51 \mathrm{mg} \mathrm{HME} \mathrm{mL}^{-1}$ and $28.62 \mathrm{mg} \mathrm{HME} \mathrm{mL}^{-1}$ in run 3 and run 10, respectively.

While the other investigated responses depended only on ethanol concentration, either as quadratic or both linear and quadratic factor, RSA IC $\mathrm{C}_{50}$ displayed somewhat different behavior. RSA $I_{50}$ was significantly negatively affected by temperature as linear factor indicating that the substances with radical scavenging abilities are thermostabile compounds whose solubility increases at high temperatures. Furthermore, it was positively affected by the interaction of temperature with ethanol concentration. Furthermore, $\mathrm{RSA} \mathrm{IC}_{50}$ was positively affected by $\mathrm{pH}$ as linear factor and negatively by its interaction with temperature. Detrimental influence of high pH on RSA was further stressed by positive influence of $\mathrm{pH}$ as quadratic factor on RSA IC $C_{50}$. The importance of temperature and $\mathrm{pH}$ for RSA I $\mathrm{C}_{50}$ has been recorded before. ${ }^{[27]}$ It is well-accepted and documented that the natural phenolic compounds are good radical scavengers. Their content often correlates with DPPH RSA. ${ }^{[32]}$ However, in this research the content of the investigated groups of phenolic compounds and RSA IC 50 were influenced by different parameters. Low influence of the polyphenols on radical scavenging activity may also be inferred from the fact that the determination coefficient for correlation between RSA $I_{50}$ and TP, TF, TPA as well as individual flavonoid derivatives content were all very low $\left(0.0098<r^{2}<0.0457\right)$ with $P>0.05$ deeming them highly insignificant. Knowing that besides phenolic compounds, other compounds present in L. corniculatus, such as carotenoids, ${ }^{[33]}$ proteins, ${ }^{[34]}$ and polysaccharides ${ }^{[35]}$ also posses antiradical abilities, it may be postulated that they are at least partly responsible for the observed antiradical activity.

Table 4. Optimal extraction conditions with predicted and experimental values of the responses.

\begin{tabular}{|c|c|c|c|c|c|c|c|c|}
\hline Response & Unit & Goals & $X_{1} / \%(v / v)$ & $X_{2} /{ }^{\circ} \mathrm{C}$ & $x_{3}$ & Response $_{\text {pred }}$ & Response $_{\exp }$ & Deviation*/\% \\
\hline Yield & $\mathrm{mg} \mathrm{mL}^{-1}$ & Maximal & 30 & 30 & 5.5 & 17.89 & 18.91 & +5.4 \\
\hline $\mathrm{TP}$ & $m g \mathrm{~mL}^{-1}$ & Maximal & 40 & 60 & 8.0 & 9.44 & 10.12 & +6.7 \\
\hline TF & $m g \mathrm{~mL}^{-1}$ & Maximal & 100 & 60 & 8.5 & 0.50 & 0.48 & +4.2 \\
\hline TPA & $m g \mathrm{~mL}^{-1}$ & Maximal & 40 & 20 & 5.5 & 0.11 & 0.10 & -10.0 \\
\hline Quercetin & $\mu \mathrm{g} \mathrm{mL} \mathrm{m}^{-1}$ & Maximal & 50 & 60 & 8.5 & 60.41 & 65.10 & +7.2 \\
\hline Kaempferol & $\mu g \mathrm{~mL}^{-1} \mathrm{~L}$ & Maximal & 50 & 60 & 8.5 & 86.72 & 92.75 & +6.5 \\
\hline Genistein & $\mu \mathrm{g} \mathrm{mL^{-1 }}$ & Maximal & 50 & 60 & 8.5 & 13.97 & 15.01 & +6.9 \\
\hline $\mathrm{IC}_{50} \mathrm{RSA}$ & $m g ~ H M E ~ m L^{-1} L$ & Minimal & 0 & 60 & 7.0 & 7.90 & 8.38 & +5.7 \\
\hline
\end{tabular}

$X_{1}$-Ethanol concentration; $X_{2}-$ Temperature; $X_{3}-\mathrm{pH}$ of extraction solvent;

TP - Total phenol content; TF - Total flavonoid content; TPA - Total phenolic acid content; RSA -Radical scavenging activity; HME - Herbal material equivalents. Response $_{\text {pred/exp }}$ - Predicted and experimental response, respectively (units are as in the Response column).

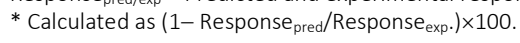




\section{Validation of Optimal Extraction Conditions}

The aim of this study was to maximize the total extraction yield, the yield of the target compounds (TP, TF, TPA and individual flavonoid derivatives), as well as DPPH radical scavenging activity of the $L$. corniculatus extracts, within studied extraction parameters range. Based on the experimental results and statistical analysis, numerical optimizations have been conducted in order to establish the optimum levels of independent variables (Table 4). As previously mentioned, the most important extraction factor was ethanol concentration. It is well known that the extraction solvent greatly affects the extraction efficiency. However, the ethanol content needed for the optimal extraction of phenolic compounds may vary according to the plant material. For example, the most suited ethanol contents for extraction of phenolic acids from Lycium ruthenicum $^{[23]}$ and isoflavonoids from Pueraria lobata ${ }^{[36]}$ were $33 \%$ and $41 \%$, respectively. Accordingly, the optimal ethanol content for extraction of individual phenolics in this study varied as well. In general, most plant constituents were best extracted using moderate ethanol concentration as reflected in the maximized yield at $30 \%$ ethanol and maximized TP and TPA at $40 \%$ ethanol. TF, on the other hand, was highest when $100 \%$ ethanol was used for the extraction. When the attention was focused on quercetin, genistein and kaempferol derivatives, it was revealed that their extraction was best achieved using $50 \%$ ethanol. The selected conditions were applied in preparation of extracts with the desired properties. The predicted results matched well with the experimental ones, with relatively low deviations from calculated values, indicating good suitability of the selected models (Table 4).

\section{CONCLUSIONS}

In the present study, RSM using Box-Behnken design was successfully employed to optimize the extraction conditions for functional components of $L$. corniculatus aerial parts. Tenfold difference in quercetin and kaempferol content between individual extracts confirms the hypothesis that the extraction conditions greatly influence the phenolic content and composition of $L$. corniculatus extracts. In addition, presence of genistein derivatives was reported in the $L$. corniculatus for the first time. The results have shown that the most important variable for achievement of high content of various phenolic compounds was ethanol concentration, while the temperature was the most important factor that influenced antiradical activity of the extracts. Optimized L. corniculatus extracts have a very high flavonoid content which opens the possibility of their use in preparation of health-related products such as food supplements or functional foods.
Acknowledgment. We kindly thank Vedran Šegota, expert associate at the Department of Botany, Faculty of science, University of Zagreb for identification of plant material. The financial support of University of Zagreb in the frame of the project Isolation and modulation of antioxidant properties of plant polyphenols by the use of cyclodextrins is kindly acknowledged

\section{REFERENCES}

[1] Q. Xu, Y. Shen, H. Wang, N. Zhang, S. Xu, L. Zhang, Food Chem. 2013, 138, 2122-2129.

https://doi.org/10.1016/j.foodchem.2012.11.099

[2] F. Perez-Vizcaino, C. G. Fraga, Arch. Biochem. Biophys. 2018, 646, 107-112.

https://doi.org/10.1016/j.abb.2018.03.022

[3] Z. Chen, S. Zheng, L. Li, H. Jiang, Curr. Drug Metab. 2014, 15, 48-61.

https://doi.org/10.2174/138920021501140218125020

[4] J. Reynaud, M. Jay, J. Raynaud, Phytochemistry 1982, 21, 2604-2605.

https://doi.org/10.1016/0031-9422(82)85271-0

[5] T. Nikolić, T. Kovačić, Flora of Medvednica (Flora Medvednice, in Croatian), Školska Knjiga, Zagreb, 2008.

[6] H. Hedqvist, I. Mueller-Harvey, J. D. Reed, C. G. Krueger, M. Murphy, Anim. Feed Sci. Technol. 2000, 87, 41-56.

https://doi.org/10.1016/\$0377-8401(00)00178-4

[7] O. Tusevski, M. Trpevski, I. Lozanovska, A. Talevska, D. Ugurovska, S. Gadzovska Simic, Bull Biol Stud Res Soc 2010, 4, 103-111.

[8] J. Koelzer, D. A. Pereira, J. B. Dalmarco, M. G. Pizzolatti, T. S. Fröde, Food Chem. 2009, 117, 444-450. https://doi.org/10.1016/j.foodchem.2009.04.044

[9] J. Dalmarco, E. Dalmarco, J. Koelzer, M. Pizzolatti, T. Frode, Int. J. Green Pharm. 2010, 4, 108-114. https://doi.org/10.4103/0973-8258.63886

[10] S. Rafiq, R. Majeed, A. K. Qazi, B. A. Ganai, I. Wani, S. Rakhshanda, Y. Qurishi, P. R. Sharma, A. Hamid, A. Masood, et al., Phytomedicine Int. J. Phytother. Phytopharm. 2013, 21, 30-38. https://doi.org/10.1016/j.phymed.2013.08.005

[11] C. A. Ramírez-Restrepo, T. N. Barry, N. LópezVillalobos, P. D. Kemp, T. G. Harvey, Anim. Feed Sci. Technol. 2005, 121, 23-43.

https://doi.org/10.1016/j.anifeedsci.2005.02.006

[12] A. Elgersma, K. Søegaard, S. K. Jensen, J. Agric. Food Chem. 2013, 61, 11913-11920. https://doi.org/10.1021/jf403195v

[13] Y. Riciputi, E. Diaz-de-Cerio, H. Akyol, E. Capanoglu, L. Cerretani, M. F. Caboni, V. Verardo, Food Chem. 2018, 269, 258-263. https://doi.org/10.1016/j.foodchem.2018.06.154 
[14] J. P. Maran, B. Priya, J. Food Sci. Technol. 2016, 53, 792-799. https://doi.org/10.1007/s13197-015-1988-8

[15] D. Ryu, E. Koh, Food Anal. Methods 2019, 12, 13821389. https://doi.org/10.1007/s12161-019-01462-2

[16] V. L. Singleton, R. Orthofer, R. M. Lamuela-Raventós, in Methods Enzymol., Academic Press, 1999, pp. 152-178.

https://doi.org/10.1016/S0076-6879(99)99017-1

[17] S. Kumazawa, T. Hamasaka, T. Nakayama, Food Chem. 2004, 84, 329-339.

https://doi.org/10.1016/\$0308-8146(03)00216-4

[18] C. Nicolle, A. Carnat, D. Fraisse, J.-L. Lamaison, E. Rock, H. Michel, P. Amouroux, C. Rémésy, J. Sci. Food Agric. 2004, 84, 2061-2069.

https://doi.org/10.1002/jsfa.1916

[19] L. M. Martin, M. C. Castilho, M. I. Silveira, J. M. Abreu, J. Liq. Chromatogr. Relat. Technol. 2006, 29, 2875-2884.

https://doi.org/10.1080/10826070600961076

[20] G. Kleinschmidt, in J Ermer J H McB Mill. Eds Method Valid. Pharm. Anal. Guide Best Pract., Wiley-VCH Verlag, Weinheim, 2005, pp. 195-212.

[21] B. Fumić, M. Jug, M. Z. Končić, Croat. Chem. Acta 2017, 90, 481-491.

https://doi.org/10.5562/cca3228

[22] D. Del Rio, A. Rodriguez-Mateos, J. P. E. Spencer, M. Tognolini, G. Borges, A. Crozier, Antioxid. Redox Signal. 2013, 18, 1818-1892.

https://doi.org/10.1089/ars.2012.4581

[23] S. Chen, Z. Zeng, N. Hu, B. Bai, H. Wang, Y. Suo, Food Chem. 2018, 242, 1-8.

https://doi.org/10.1016/j.foodchem.2017.08.105

[24] Z. Jurasekova, A. Torreggiani, M. Tamba, S. SanchezCortes, J. V. Garcia-Ramos, J. Mol. Struct. 2009, 918, 129-137.

https://doi.org/10.1016/j.molstruc.2008.07.025
[25] K. I. Berker, F. A. Ozdemir Olgun, D. Ozyurt, B. Demirata, R. Apak, J. Agric. Food Chem. 2013, 61, 4783-4791. https://doi.org/10.1021/jf400249k

[26] Ö. Aybastıer, E. Işık, S. Şahin, C. Demir, Ind. Crops Prod. 2013, 44, 558-565.

https://doi.org/10.1016/j.indcrop.2012.09.022

[27] M. Heydari Majd, A. Rajaei, D. Salar Bashi, S. A. Mortazavi, S. Bolourian, Ind. Crops Prod. 2014, 57, 195202. https://doi.org/10.1016/j.indcrop.2014.03.031

[28] D. Mammen, M. Daniel, Food Chem. 2012, 135, 1365-1368. https://doi.org/10.1016/j.foodchem.2012.05.109

[29] L. Sarelli, M. Tuori, I. Saastamoinen, L. Syrjälä-qvist, H. Saloniemi, Acta Agric. Scand. Sect. - Anim. Sci. 2003, 53, 58-63. https://doi.org/10.1080/09064700310002053

[30] V. Mukund, D. Mukund, V. Sharma, M. Mannarapu, A. Alam, Crit. Rev. Oncol. Hematol. 2017, 119, 13-22. https://doi.org/10.1016/j.critrevonc.2017.09.004

[31] N. Irrera, G. Pizzino, R. D’Anna, M. Vaccaro, V. Arcoraci, F. Squadrito, D. Altavilla, A. Bitto, Nutrients 2017, 9, 622. https://doi.org/10.3390/nu9060622

[32] M. Friščić, M. Štibrić Baglama, M. Milović, K. Hazler Pilepic, Z. Males, Croat. Chem. Acta 2018, 91, 411417. https://doi.org/10.5562/cca3379

[33] L. C. R. dos Reis, E. M. P. Facco, M. Salvador, S. H. Flôres, A. de Oliveira Rios, J. Food Sci. Technol. 2018, 55, 2679-2691. https://doi.org/10.1007/s13197-018-3190-2

[34] J. M. Krochta, J. S. Hudson, Tillin, in Pyrolysis Oils Biomass, American Chemical Society, 1988, pp. 119128. https://doi.org/10.1021/bk-1988-0376.ch012

[35] Z. Zhang, F. Kong, H. Ni, Z. Mo, J.-B. Wan, D. Hua, C. Yan, Carbohydr. Polym. 2016, 144, 106-114. https://doi.org/10.1016/j.carbpol.2016.02.030

[36] K. H. Wong, G. Q. Li, K. M. Li, V. Razmovski-Naumovski, K. Chan, Food Chem. 2017, 231, 231-237. https://doi.org/10.1016/j.foodchem.2017.03.068 